\title{
ANÁLISIS MORFOMÉTRICO Y ULTRAESTRUCTURAL DE COMPONENTES ASOCIADOS A SÍNTESIS PROTEICA EN CÉLULAS MAMARIAS NORMALES Y TRANSFORMADAS
}

\author{
MORPHOMETRIC AND ULTRASTRUCTURAL ANALYSIS OF COMPONENTS ASSOCIATED \\ TO PROTEIN SYNTHESIS IN NORMAL AND TRANSFORMED MAMMARY CELLS
}

Ricardo Cornejo U.

\begin{abstract}
CORNEJO, U. R. Análisis morfométrico y ultraestructural de componentes asociados a síntesis proteica en células mamarias normales y transformadas. Int. J. Morphol., 22(3):221-224, 2004.

RESUMEN: Las células mantenidas en cultivo que conservan sus características propias, constituyen un excelente modelo para el estudio de las modificaciones fisiológicas, morfológicas y morfométricas que caracterizan el proceso biológico de la transformación celular.

La línea HC11 corresponde a células de epitelio mamario de rata, normales, mantenidas en cultivo, las cuales estimuladas a proliferar con factor de crecimiento epidérmico originan el grupo celular HC11 GM. Cuando estas células normales y proliferantes son transfectadas con el oncogen ras, se determina la generación de un tipo celular transformado, el cual por efecto de las sucesivas mitosis deriva en el grupo celular HC11ras.
\end{abstract}

Estudios de microscopía electrónica, morfológicos y morfométricos permiten establecer cómo las particularidades de los distintos constituyentes celulares se traducen en la función celular, y por ende, precisar el padrón de modificación ultraestructural que caracteriza el mecanismo de transformación, relacionando básica y comparativamente los componentes involucrados en la síntesis de proteínas mamarias.

PALABRAS CLAVE 1. Transformación celular; 2. Morfometría; 3. Glándula mamaria.

\section{INTRODUCCIÓN}

La línea celular de glándula mamaria HC11, constituye un sistema apropiado para estudiar la transformación de una célula normal en cancerosa. Esta modificación en el fenotipo puede tener como agente causal, los efectos producidos por una transfección con oncogenes, los cuales producen alteraciones tanto genéticas como epigenéticas que llevan directamente a la alteración de la expresión génica (Perroteau et al., 1986).

Al respecto, Hynes et al. (1992), demostraron que la introducción en células HC11 de proteína Ha-ras activada se traduce en la transformación de esta línea celular con una consiguente inhibición en la síntesis de beta caseína, principal proteína láctea. De igual manera, Happ et al., (1993) mostraron que cuando células HC11 son transfectadas con el oncogén ras, éstas asumen propiedades transformadas llevando a un bloqueo tanto del factor de transcripción específico de la glándula mamaria como de la transcripción del gen para beta caseína, resultando, por lo tanto, tipos celulares transformados, incapaces de sintetizar esta proteína de la leche.

En este sentido, ha sido reconocido también que el oncogen ras transformante provoca una malignización característica de la célula neoplásica que se traduce en una marcada indiferenciación (Bersntein \& Weiberg, 1985). Del mismo modo, Ellisen (1998) ha informado en relación a fundamentales variaciones en el fenotipo de células normales de gran variedad de órganos, en la medida que se transforman debido a la funcionalidad de los oncogenes diversos, incluyendo el ras.

En este contexto, Bal De Kier \& Adam (2001) describen con claridad la participación del oncogén ras como responsable de los complejos procesos de transformación maligna, evidenciando las diferencias sustantivas entre células normales y neoplásicas. 


\section{MATERIAL Y MÉTODO}

Microscopía electrónica de transmisión. Al pellet que contenía las células HC11 GM, y HC11ras se le adicionó solución de glutaraldehído $2 \%$, en tampón fosfato 0,15 $\mathrm{M}, \mathrm{pH} 7,2$, y se mantuvo a temperatura ambiente, por 2 horas. Posteriormente, fue sometido a un lavado en solución de $6 \mathrm{~g}$ de $\mathrm{NaCl}$ y $73 \mathrm{~g}$ de sacarosa, disueltos en 1 litro de agua destilada.

La post-fijación se realizó en solución de tetróxido de osmio $1 \%$, disuelto en la solución de lavado antes descrita, durante una hora, a $40^{\circ} \mathrm{C}$ y acetato de uranilo $0,5 \%$, por 18 horas. Luego de lavado el material fue deshidratado en concentraciones crecientes de acetona (30 a 100\%) e incluido en Araldita 6005. Se obtuvieron cortes ultrafinos de, aproximadamente, $70 \mathrm{~nm}$ de grosor, los que fueron tratados con acetato de uranilo $2 \%$, durante 40 minutos y citrato de plomo $0,5 \%$, por 10 minutos.

Las muestras fueron estudiadas y fotografiadas en un microscopio electrónico Phillips EM 400.

Método estereológico. A partir de los bloques para microscopía electrónica, fueron obtenidos cortes ultrafinos, en los cuales se micrografiaron cada uno de los tipos celulares, con aumento de $23.000 \mathrm{X}$.

Para la evaluación de las fracciones volumétricas de los diferentes componentes celulares, fue sobrepuesto un retículo de puntos, en las micrografías electrónicas y se procedió al conteo diferencial de los puntos que incidían sobre los perfiles de los componentes celulares, calculándose la fracción volumétrica que un determinado componente ocupa, mediante la siguiente ecuación:

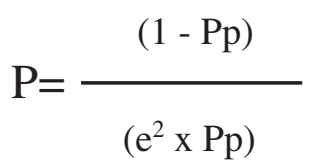

Donde:

$\mathrm{P}=$ número total de puntos incidentes sobre la unidad de volumen $\mathrm{Pp}=$ estimativa previa de la fracción volumétrica del componente en estudio

e $=$ error patrón relativo que se desea tener asociado a la fracción volumétrica

Para el cálculo del perímetro celular fue utilizado el analizador de imagen Diámetro FERET (Sigma Scann Pro).

\section{RESULTADOS}

Descripción morfológica de los tipos celulares correspondiente a epitelio mamario, a nivel ultraestructural. La Fig. 1. ilustra la morfología del tipo celular normal (HC11 GM), perteneciente a glándula mamaria, pudiendo observarse claramente que esta célula posee un núcleo voluminoso de aspecto regular, conteniendo mayoritariamente eucromatina y con pequeños acúmulos de heterocromatina unidos a la envoltura nuclear.

A nivel citoplasmático existen mitocondrias fusiformes regularmente dispuestas, cisternas de retículo endoplasmático rugoso dilatadas conteniendo material intracisternal, escasos lisosomas y gran cantidad de ribosomas libres.

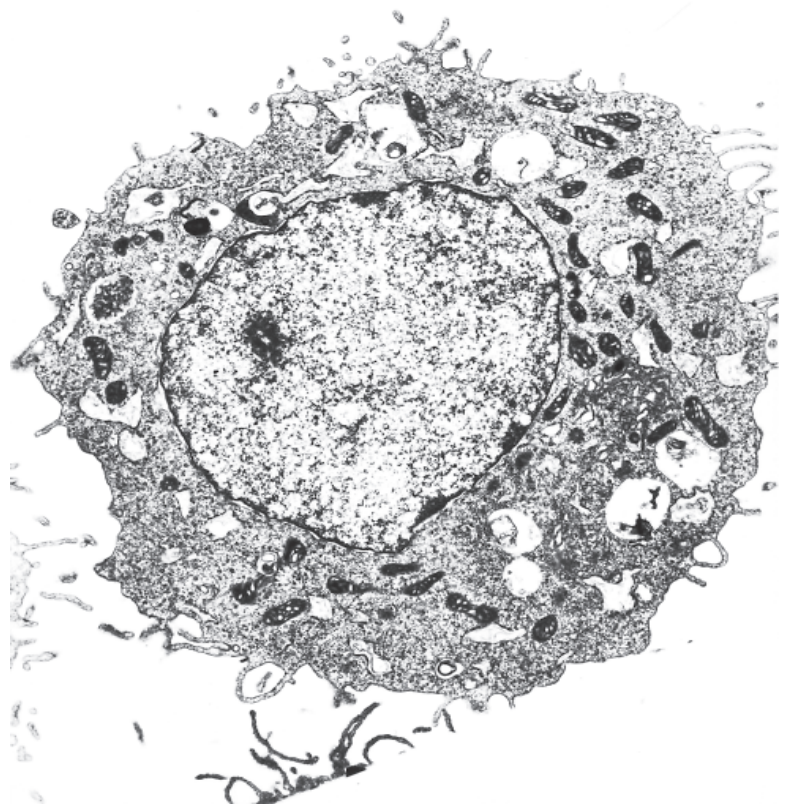

Fig. 1 Micrografía electrónica del tipo celular normal HC11 de glándula mamaria. $10.500 \mathrm{X}$.

Por otra parte, la Fig. 2 describe la morfología del tipo celular transformado HC11ras evidenciándose un núcleo voluminoso de contorno irregular, el cual contiene heterocromatina dispuesta regularmente y uno o más nucléolos son claramente observables.

Mitocondrias elípticas aparecen regularmente esparcidas por la masa citoplasmática, además, tanto ribosomas libres como cisternas de retículo granular y complejo de Golgi son claramente visibles. Sin embargo, la principal característica de este tipo celular es la gran cantidad de lisosomas secundarios, bajo la forma de cuerpos multivesiculares dispersos por todo su citoplasma. 
Análisis morfométrico de los tipos celulares normales y transformados de epitelio mamario. Los análisis mofométricos fueron realizados a partir de las micrografías electrónicas obteni-

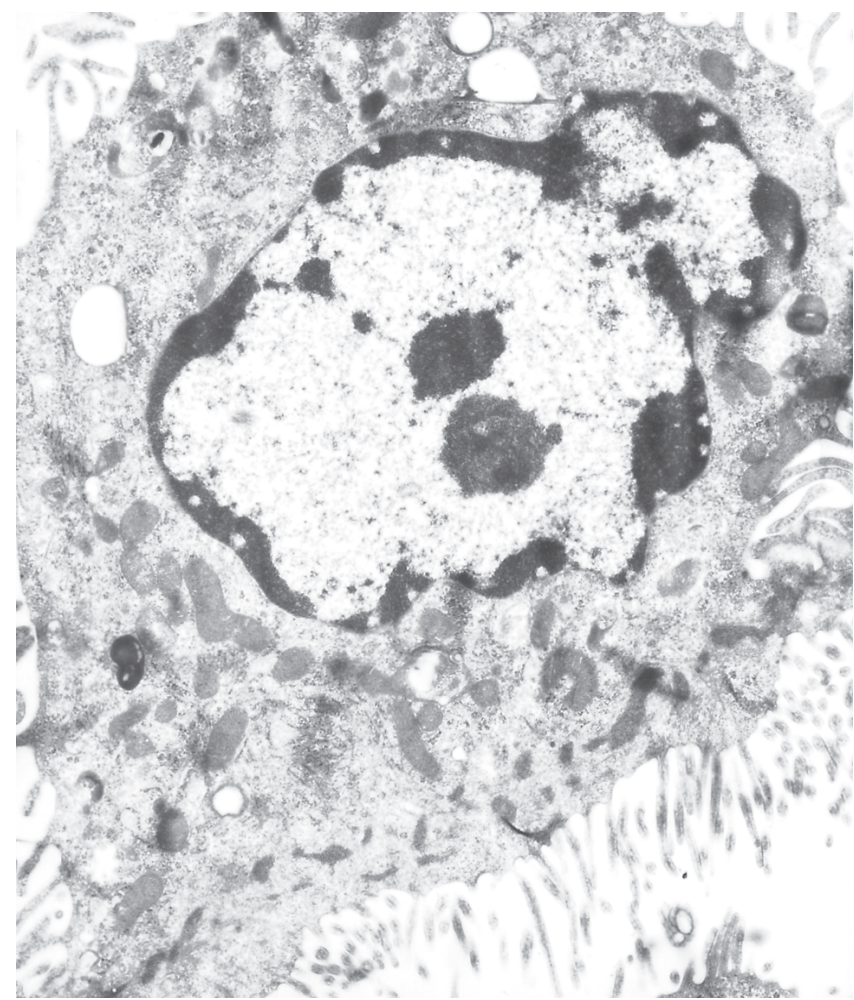

Fig. 2. Micrografía electrónica del tipo celular transformado HC11ras de glándula mamaria. $10.500 \mathrm{X}$.

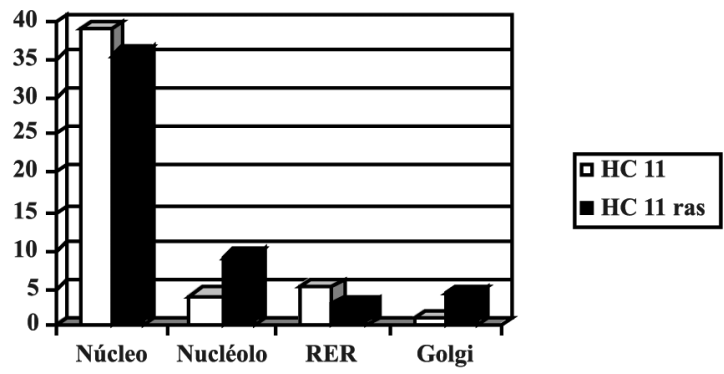

Gráfico I. Fracciones volumétricas (\%) correspondientes a componentes de células mamarias normales y transformadas asociadas a síntesis proteica.

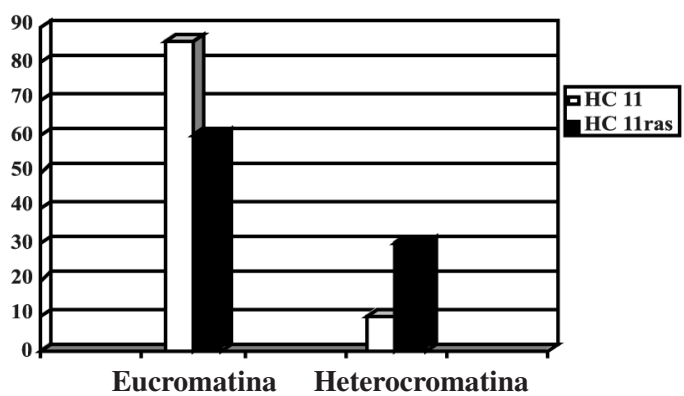

Gráfico I. Fracciones volumétricas (\%) correspondientes a cromatina de células mamarias normales y transformadas. das de los tipos celulares tanto normales como transformados, caracterizados anteriormente desde el punto de vista ultraestructural.

Los gráficos que se presentan permiten evaluar la variación de las fracciones volumétricas de cada uno de los diferentes componentes celulares, en medida que acontece el mecanismo de la transformación celular en este sistema biológico.

El Gráfico I describe el resultado de la evaluación morfométrica, determinándose las fracciones volumétricas de los siguentes componentes asociados a la síntesis de proteínas mamarias: núcleo, nucleólo, retículo endoplasmático rugoso y complejo de Golgi, pertenecientes tanto a células normales como transformadas.

En este mismo contexto, el Gráfico II evidencia las fracciones volumétricas correspondientes a los tipos de cromatina, evaluados mediante las técnicas morfométricas, tanto en HC11 GM como en HC11ras.

El perímetro celular de las células mamarias normales HC11 era de $40 \mu$, mientras que en las células transformadas HC11 ras fue de $53 \mu$.

\section{DISCUSIÓN}

Del análisis de los resultados presentados, fundamentalmente los relativos a las fracciones volumétricas de componentes tales como el núcleo, eu y heterocromatina y sobre todo la disminución de los volumenes ocupados por el retículo endoplasmático rugoso en HC11ras, se concluye que la célula transformada presentan una tasa de síntesis y secreción proteica muy disminuida con respecto a la exibida por el tipo normal.

Al respecto, Hynes et al. demostraron que las células HC11 en crecimiento sintetizan y secretan las glicoproteínas laminina y tenascina, pudiendo ser visualizadas tanto en el citoplasma en forma de vacuolas como en el espacio extracelular como fibrillas finas.

Por tanto, resulta tentador suponer que esta situación sea el resultado de una exacerbación de la síntesis de proteínas en los ribosomas libres, utilizadas para enfrentar el consumo interno generado por los activos mecanismos mitóticos característicos de este tipo celular neoplásico, situación ya demostrada por Barbacid (1986).

En directa relación a los hechos mostrados anteriormente, la cuantificación relativa a la fracción volumétrica del nucleólo que aparece duplicada en HC11 ras, argumenta fuertemente a favor de un apreciable incremento en la biosíntesis de ribosomas libres por este tipo celular. 
Estas variaciones tanto en los volúmenes de los componentes como en el fenotipo y por tanto en su funcionalidad, observados en estas células mamarias, son coicidentes con las comunicadas por Lindblom \& Liljegren (2000), autores que evidencian modificaciones celulares semejantes a las descritas para $\mathrm{HC} 11$.

Es relevante discutir en relación al evidente aumento de volumen que experimenta la célula transformada en relación a la normal, pudiendo argumentarse que estos 13 micrones de diferencia entre los perímetros de ambos tipos celulares sea respon- sable, por un lado, de un incremento notable de componentes citoplasmáticos tales como mitocondrias y lisosomas secundarios (datos no mostrados), como también esta diferencia de masa citoplasmática se pueda deber a un estadio pre-mitótico determinado para enfrentar, posteriormente, el mecanismo divisionario.

En este mismo contexto, sin embargo, este aumento en el perímetro celular de HC11ras, según Cotrán et al. (1999) es característico de células en procesos neoplásicos que llevan a la formación de grandes células cancerosas, situación que se describe claramente en este sistema.

CORNEJO, U. R. Morphometric and ultrastructural analysis of components associated to protein synthesis in normal and transformed mammary cells. Int. J. Morphol., 22(3):221-224, 2004.

SUMMARY: Those cells which preserve their own characteristics under culture are a good model to study physiological, morphological and morphometrical changes, especially when are submitted to the process of cellular transformation. The normal HC11 cells belong to rat mammary epithelium culture which can be stimulated to proliferate by epidermal growth factor, which turn them into a new cell group named HC11 GM. When both normal and proliferative cells are transfected with the oncogen ras, a new transformed cell type is generated which after several mitosis, turns into the cell group HC11 ras.

Morphological, morphometric and electronic microscopy studies on those cells allow to establish how their special particularities and constituents are translated into cell function and ultrastructural modification. The transformation mechanism is mainly based on mamary gland protein synthesis.

KEY WORDS: 1. Cellular transformation; 2. Morphometry; 3. Mammary Glands.

\section{REFERENCIAS BIBLIOGRÁFICAS}

Bal De Kier, E. \& Adam, A. Transformación celular y mecanismos de sobrevida regulados por la GTPasa Ral. Medicina, 61: 658-63, 2001.

Barbacid, M. Human oncogens. In: De Vita, V. T.; Hellmans, S.; Rosenberg, S.A. Important advances in oncology. Philadelphia, Lippincott, 1986, 3-32.

Bernstein, S. C. \& Weinberg, R. A. Expression of the metastatic phenotype in cells transfected with human metastatic tumor DNA. Proc. Natl. Acad. Sci., 82:172630, 1985.

Cotrán, R.S.; Kumar, V. \& Collins, T. Robbins pathologic basis of disease. 6. ed. Philadelphia, Saunders, 1999.

Ellisen, W. Mechanisms of tumor suppressor genes. Science \& Medicine, July: 26-35, 1998.

Happ, B.; Hynes, N. E. \& Groner, B. Ha-ras and v-raf oncogenes, but not int-2 and c-myc, interfere with the lactogenic hormone dependent activation of the mammary specific transcription factor. Cell Growth and Differentiation, 4:9-15, 1993.
Hynes, N.E.; Taverna, D.; Cella, N. \& Chammas, R. The effect of the extracelular matriz upon HC11 mammary epithelial cell differentiation. Ciencia e Cultura, 44:2536, 1992.

Lindblom, A. \& Liljegren, A. Tumour markers in malignancies. BMJ, 320: 424-28, 2000.

Perroteau, I.; Salomon, D.S.; De Bertoli, M.; Kidwell, W.R.; Hazarika, P.; Pardue, R.; Dedman, J. \& Tam, J. Innunological detection and quantitation of alphatransforming growth factor in human breast carcinoma cells. Breast Cancer Res Treta., 7:201-10, 1986.

Dirección para correspondencia:

Prof. Dr. Ricardo Cornejo Ulibe

Facultad de Medicina

Universidad de La Frontera

Casilla $54-\mathcal{D}$

Recibido : 08-08-2003

Temuco-CHILE
Aceptado:16-07-2004 